\title{
Research of Nanostructures Formation during Self-Propagating High-Temperature Synthesis of Boride-Containing Composite Materials
}

\author{
D. S. Raimkhanova, R. G. Abdulkarimova, Z. A. Mansurov \\ Institute of Combustion Problems, Almaty, Kazakhstan \\ Email: Abd.danara@mail.ru
}

Received October 2013

\begin{abstract}
This paper considers the technique of obtaining boride-containing nanostructured composite materials by the method of self-propagating high-temperature synthesis (SHS). It is shown that the selection of regimes and conditions of reactions allows receiving materials on the basis of titanium and chromium borides as well as aluminum oxide with finely dispersed structure and high mechanical properties.
\end{abstract}

\section{KEYWORDS}

\section{Aluminum Oxide; Titanium Diboride; Chromium Diboride; Composite Materials;} Nanomaterials; SHS

\section{Introduction}

Obtaining ceramic and composite materials containing nano-sized phase and structural components is currently one of the most important problems. One of the trends for solving such problems is a combination of several technological techniques allowing modifying the material structure directionally at the stage of preparation and carrying out of subsequent synthesis [1,2]. Among various methods of synthesis on the basis of reactions, the synthesis in the mode of self-propagating high-temperature synthesis (SHS) is particularly attractive because of its advantages: low energy consumption, short process time, simplicity of equipment and the formation of products with high purity, etc. [1-3].

Diborides of transition metals such as $\mathrm{TiB}_{2}$ and $\mathrm{CrB}_{2}$ have many excellent properties such as high melting point, high density, good thermal and electrical conductivity, excellent wear and corrosion resistance and chemical stability [1-3]. Furthermore, adding $\mathrm{Al}_{2} \mathrm{O}_{3}$ to the borides of these metals improves their breaking strength, flexural strength, impact strength and this makes boride composites very promising for a wide range of applications, including cutting tools, wear-proof parts and high temperature structural materials $[2,3]$.

\section{Methodology of Experiment}

\subsection{Self-Propagating High-Temperature Synthesis}

The purpose of this research is to study the $\mathrm{SH}$-synthesis of composites based on $\mathrm{TiB}_{2}-\mathrm{Al}_{2} \mathrm{O}_{3}$ and $\mathrm{CrB}_{2}-\mathrm{Al}_{2} \mathrm{O}_{3}$ with a wide range of phase composition in the process of SHS in the systems of $\mathrm{Ti}-\mathrm{TiO}_{2}-\mathrm{B}-\mathrm{B}_{2} \mathrm{O}_{3}-\mathrm{Al}, \mathrm{Cr}_{2} \mathrm{O}_{3}-\mathrm{Al}-\mathrm{B}_{2} \mathrm{O}_{3}$, $\mathrm{TiO}_{2}-\mathrm{H}_{3} \mathrm{BO}_{3}-\mathrm{Mg}-\mathrm{nNaCl}$.

The initial components of the SHS-charge were $\mathrm{TiO}_{2}$, $\mathrm{Cr}_{2} \mathrm{O}_{3}, \mathrm{~B}_{2} \mathrm{O}_{3}$ oxides, amorphous boron and aluminum of PA-4 grade (purity of $99.1 \%$, particles $<40$ microns). The charge of a specified composition was intermixed thoroughly up to achieving a high degree of homogeneity. Cylindrical samples with a diameter of $20 \mathrm{~mm}$ and a height of $25 \mathrm{~mm}$ were pressed on an automatic press (Carver, Inc., USA) with the effort of 4 t. Experiments were performed in the air atmosphere; the initiating of $\mathrm{SH}$-synthesis was performed by thermite or magnesium.

Compositions containing $\mathrm{TiO}_{2}, \mathrm{H}_{3} \mathrm{BO}_{3}$, Mg, and various amounts of $\mathrm{NaCl}(5,10,15 \mathrm{wt} . \%)$ were prepared for conducting SH-synthesis in the system of $\mathrm{TiO}_{2}-\mathrm{H}_{3} \mathrm{BO}_{3}$ $\mathrm{Mg}-\mathrm{nNaCl}$. Educing of titanium diboride from combustion products was conducted by treating the latter with water and hydrochloric acid. 
The microstructure of synthesized products was studied by scanning electron microscope-micro-analyzer JCXA-733 (JEOL) "Superprobe" and SEM Hitachi S-4800 FE-SEM, Japan, the phase composition of SHS products by the X-ray diffractometer DRON-3.

\subsection{Combustion Front Quenching Method}

To study the structural transitions in the combustion of $\mathrm{Ti}-\mathrm{TiO}_{2}-\mathrm{B}-\mathrm{B}_{2} \mathrm{O}_{3}-\mathrm{Al}$ the method of combustion front quenching method (CFQM) system was used [4]. The reaction mixture was placed in a wedge-shaped notch in a copper block, and the combustion reaction was initiated by an incandescent tungsten spiral at the base of the wedge. When the combustion wave traveled toward the apex, because of the intense transfer of heat to the cooling copper block, the combustion was quenched, so the intermediate and final products of the reaction were frozen. The structures of the specimen in the regions where the front is quenched were observed with scanning electron microscopy (SEM).

\section{Results of Research and Their Discussion}

Shutting down of SHS-process with the subsequent

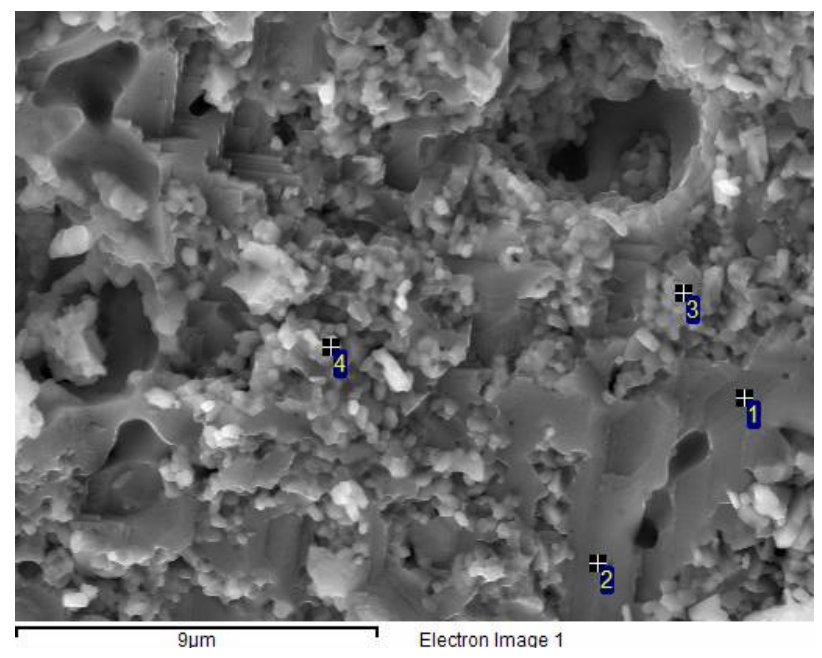

\begin{tabular}{|c|c|c|c|c|}
\hline \multirow{2}{*}{ Zone No. } & \multicolumn{4}{|c|}{ Atomic ratio, \% } \\
\hline 1 & & O & Al & Ti \\
\hline 2 & 7.76 & 57.32 & 39.69 & 2.99 \\
\hline 3 & 44.13 & 24.23 & 20.69 & 10.95 \\
\hline 4 & 49.98 & 13.43 & 7.44 & 29.14 \\
\hline
\end{tabular}

(a) analysis of partially and fully burned parts of the charge in the system of $\mathrm{Ti}-\mathrm{TiO}_{2}-\mathrm{B}-\mathrm{B}_{2} \mathrm{O}_{3}-\mathrm{Al}$ was performed. At the enlarged fragment of the reaction zone of CFQM SHS wave shown in the Figure 1(a) and (b), the formation of granular inclusions crystallized in the six-membered lamellar formations of titanium diboride in a matrix of aluminum oxide shown in the final product.

It was found that aluminum facilitates the formation of submicron particles. It can serve as the concentrator of crystal whisker growth carried out by the mechanism of "vapor-liquid-solid” [3,5].

For the system of $\mathrm{Cr}_{2} \mathrm{O}_{3}-\mathrm{B}_{2} \mathrm{O}_{3}-\mathrm{Al}$ the formation of microstructure of the solid-phase combustion products was also investigated. It can be assumed that they represent areas of a metastable solid solution of chromium diboride in aluminum oxide matrix. Studying the microstructure of compositions with higher magnification revealed the formation of whiskers from aluminum oxide in the matrix of chromium diboride [6] (Figure 2).

Figure 2 shows that whiskers are of different sizes and shapes. Fibers are of straight, curled and wavy forms (Figures 2(b)-(e)). The Figure 2(e) shows whiskers having branched structure. The results obtained show that the formation of $\alpha-\mathrm{Al}_{2} \mathrm{O}_{3}$ fibers with a length of about
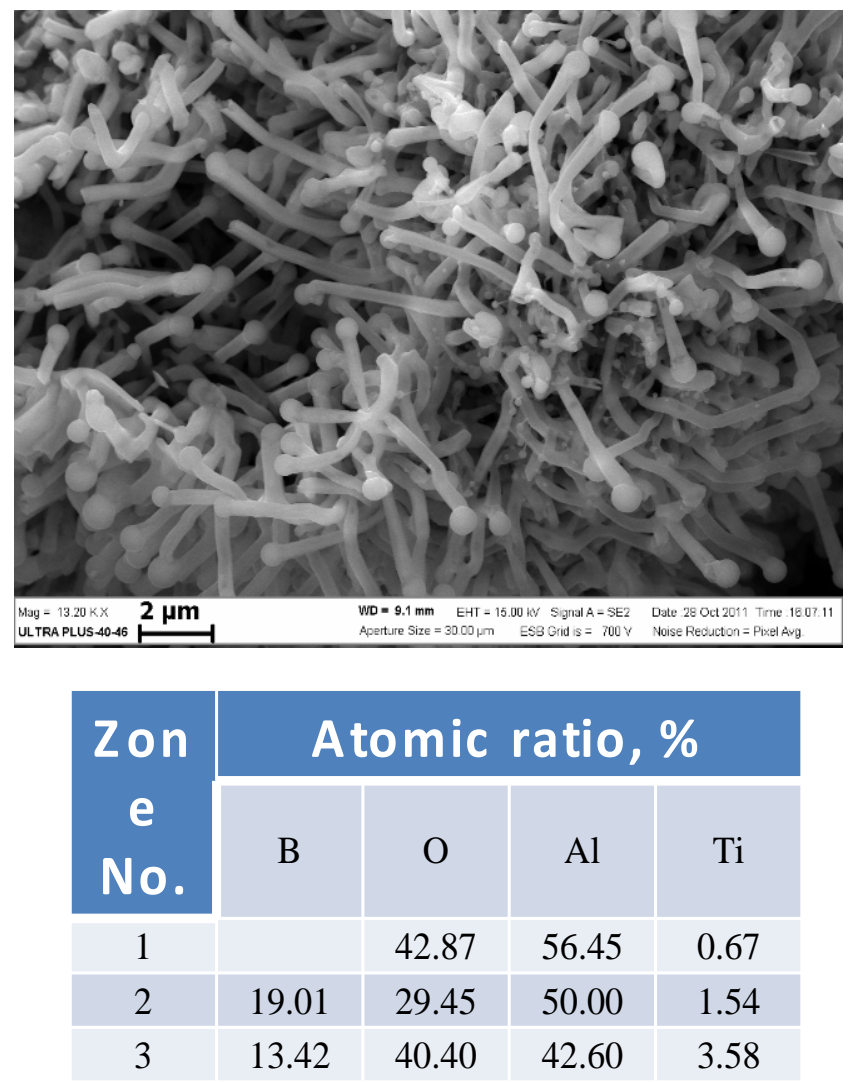

(b)

Figure 1. Analysis and microstructure of the combustion system products $\mathrm{TiO}_{2}-\mathrm{B}_{2} \mathrm{O}_{3}$-Al, obtained by the CFQM of the SHS wave; (a) reaction zone with the formation of grains of $\mathrm{TiB}_{2}$; (b) formation of $\mathrm{Al}_{2} \mathrm{O}_{3}$ fibers in the pores of reaction zone. 


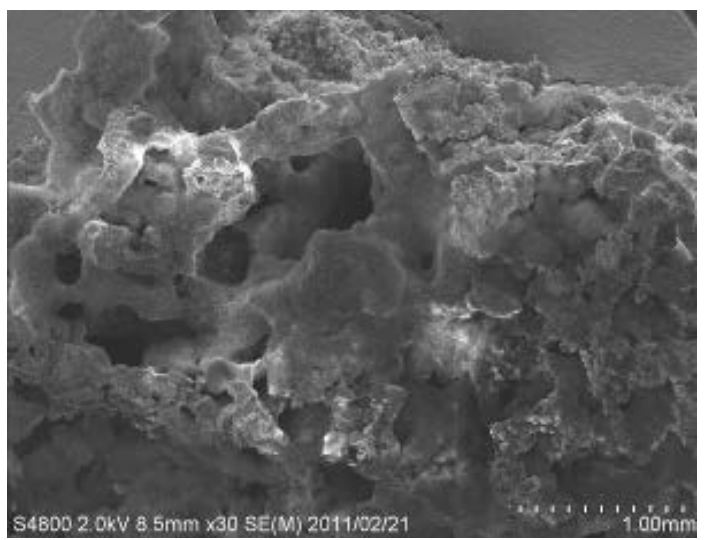

(a)

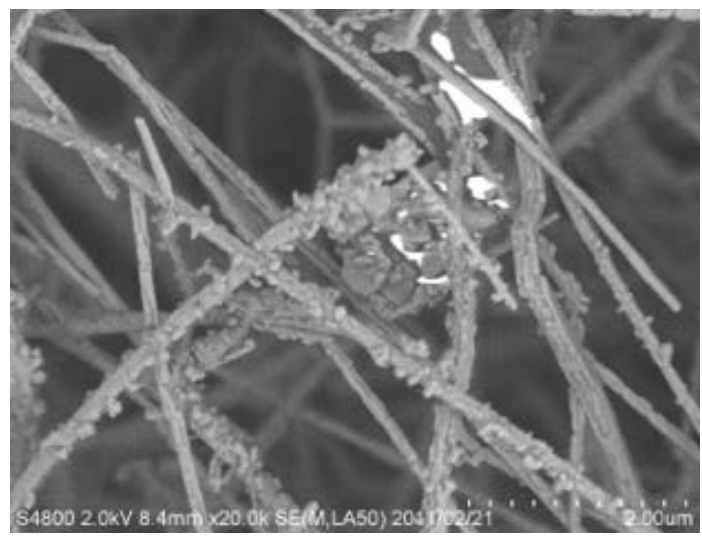

(c)

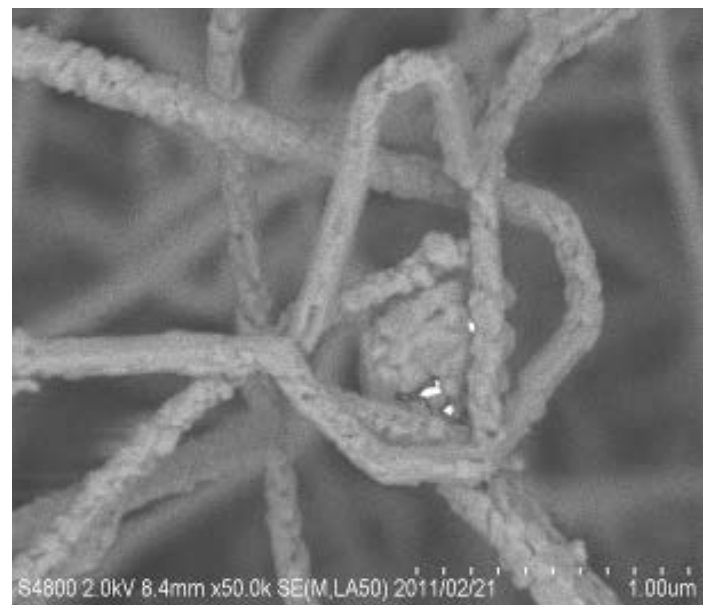

(e)

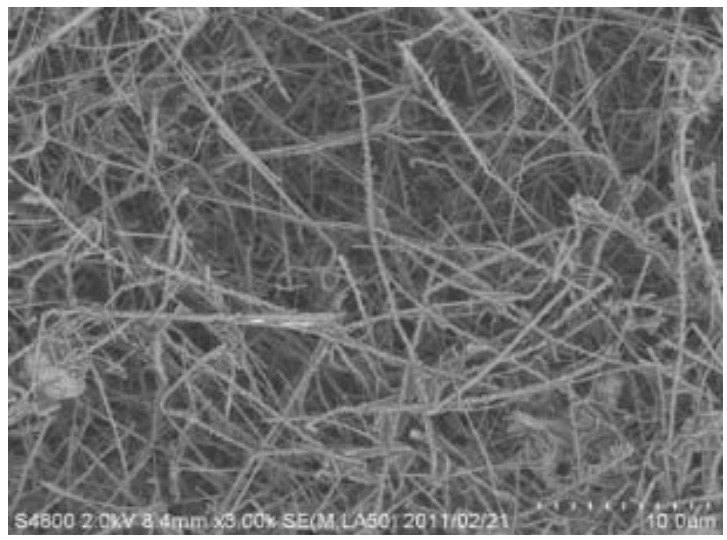

(b)

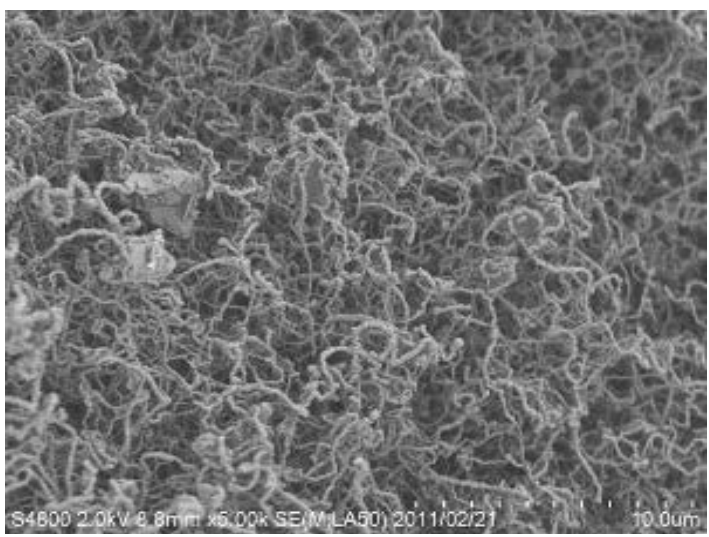

(d)

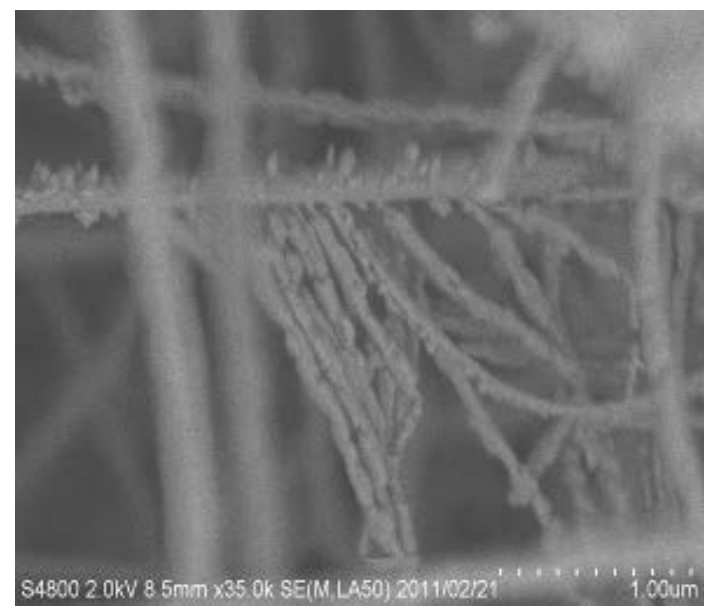

(f)

Figure 2. Microstructure of products of $\mathrm{Cr}_{2} \mathrm{O}_{3}-\mathrm{B}_{2} \mathrm{O}_{3}-\mathrm{Al}$; (a) General picture of final products surface; (b) whiskers (feathers) of aluminum oxide; (c), (d), (e) straight, wavy and twisted forms of whiskers, e-branching of multiple crystals.

$\mathrm{l}=10-25$ microne and a diameter $\mathrm{d}=200-500 \mathrm{~nm}$. Various values of the fibers diameter followed from system growth self-turbulence, namely, the growth of temperature, diffusion and chemical reaction, unevenness of the boundary between the liquid and solid phases. [3]

Thus, as a result of studies of $\mathrm{Ti}-\mathrm{TiO}_{2}-\mathrm{B}-\mathrm{B}_{2} \mathrm{O}_{3}-\mathrm{Al}$, $\mathrm{Cr}_{2} \mathrm{O}_{3}+\mathrm{Al}+\mathrm{B}_{2} \mathrm{O}_{3}$ systems, in SHS-products of studied systems was established the presence of high temperature phases-titanium diboride, chromium diboride and aluminum oxide chromium (XRD). It was established that the formation of submicron aluminum oxide whiskers in the combustion process and that they strengthen the resulting composite and improve its fire resistance up to $2000^{\circ} \mathrm{C}$. 
The product of combustion and further acidic treatment of the $\mathrm{TiO}_{2}-\mathrm{H}_{3} \mathrm{BO}_{3}-\mathrm{Mg}-\mathrm{nNaCl}$ system represented phases of titanium diboride as well as phases of $\mathrm{TiO}_{2}$ and titanium nitride TiN (Table 1).

The Figure 3 shows the roentgenogram of the obtained product after treatment with hydrochloric acid.

We studied the microstructure of the final products depending on the amount of $\mathrm{NaCl}$ diluent in the charge. Figure 4 shows microstructures of the titanium diboride powder $\mathrm{TiO}_{2}-\mathrm{H}_{3} \mathrm{BO}_{3}-\mathrm{Mg}-\mathrm{nNaCl}$ (5, 10, 15 wt.\%) system obtained in the SHS regime and its subsequent treatment with a solution of hydrochloric acid $\mathrm{HCl}$.

Table 1. XRF products after leaching.

\begin{tabular}{lrrr}
\hline \multicolumn{4}{c}{ Conent, \% } \\
\hline $\mathrm{TiB}_{2}-88.6$ & $\mathrm{TiO}_{2}-5.9$ & $\mathrm{SiO}_{2}-3.7$ & $\mathrm{TiN}-1.8$ \\
\hline
\end{tabular}

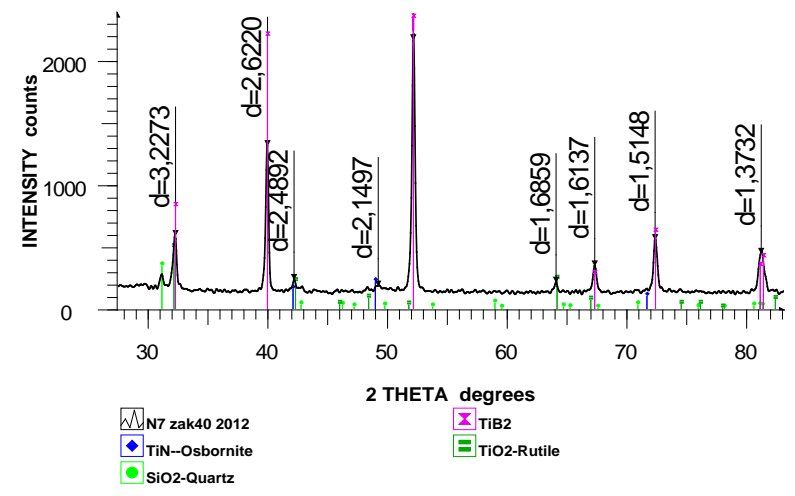

Figure 3. Roentgenogram of SHS products.

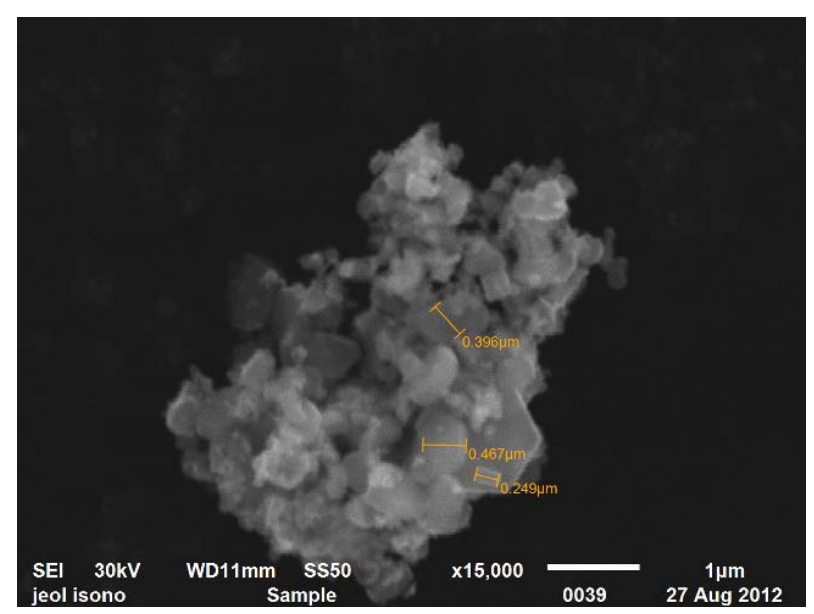

Figure 4. Scanning electron micrograph of the product after acidic treatment of $\mathrm{TiO}_{2}-\mathrm{H}_{3} \mathrm{BO}_{3}-\mathrm{Mg}-\mathrm{nNaCl}$ system $(\mathrm{n}=15$ wt. \%).
Thus, as a result of SHS with further acidic treatment with the use of $\mathrm{NaCl}$ acid with the purpose of dissolving $\mathrm{MgO}$ and other impurities, it was obtained a titanium diboride powder, which represented agglomerates consisting of spherical particles with a size of $200-1000$ $\mathrm{nm}$.

\section{Conclusion}

The directed regulation of high temperature solid-phase synthesis process allows forming composite ceramic materials based on diborides of transition metals with finely dispersed structure and high mechanical properties. This approach is used to create new, simple and cost-effective processes of creating high strength ceramics.

\section{REFERENCES}

[1] A. E. Sitschev and A. G. Merzhanov, Chemistry of Advanced Materials, Vol. 73, No. 2, 2004, pp. 157-170.

[2] E. Levashov, A. S. Rogachev, V. V. Kurbatkina, Yu. M. Maksimov and V. Yu. Yuhvid, "Advanced Materials and SHS Technologies,” Russia, 2011.

[3] D. S. Abdulkarimova (D. S. Raimhanova), "Synthesis of Composite Materials Based on Borides under the SolidBurning Regime,” Diss. Doctor of Philosophy (Ph.D.), Almaty, 2012, 116 p.

[4] A. S. Rogachev, A. S. Mukas Yan and A. G. Merzhanov, "Doklady Physical Chemistry (English Translation)," Vol. 297, 1987, pp. 1240-1243.

[5] M. A. Meyers, E. A. Olevsky, J. Ma and M. Jamet, "Combustion Synthesis/Densification of an $\mathrm{Al}_{2} \mathrm{O}_{3}-\mathrm{TiB}_{2}$ Composite," Materials Science and Engineering: A, Vol. 311, No. 1-2, 2001, pp. 93-99. http://dx.doi.org/10.1016/S0921-5093(01)00930-3

[6] Z. A. Mansurov, "Obtaining Nanomaterials in Combustion Processes,” Physics of Combustion, Vol. T48, No. 5, 2012, pp.77-86. 